\title{
Prognostic implications of HER2 heterogeneity in gastric cancer
}

\author{
Shigenobu Motoshima ${ }^{1,2}$, Koji Yonemoto ${ }^{3}$, Hideki Kamei $^{4}$, Michi Morita ${ }^{5}$ and Rin \\ Yamaguchi ${ }^{6}$ \\ ${ }^{1}$ Biostatistics Center, Graduate School of Medicine, Kurume University, Kurume, Fukuoka, Japan \\ ${ }^{2}$ Department of Clinical Laboratory, Kokura Medical Center, Kitakyushu, Fukuoka, Japan \\ ${ }^{3}$ Advanced Medical Research Center, Faculty of Medicine, University of the Ryukyus, Nishihara, Okinawa, Japan \\ ${ }^{4}$ Department of Surgery, Japan Community Health Care Organization Kurume General Hospital, Kurume, Fukuoka, Japan \\ ${ }^{5}$ Department of Surgery, Nagasaki University Graduate School of Biomedical Sciences, Nagasaki, Nagasaki, Japan \\ ${ }^{6}$ Department of Pathology and Laboratory Medicine, Kurume University Medical Center, Kurume, Fukuoka, Japan \\ Correspondence to: Rin Yamaguchi, email: rin@med.kurume-u.ac.jp
}

Keywords: gastric cancer; HER2; intratumoral heterogeneity; prognosis; trastuzumab

Received: July 11,2017 Accepted: January 09, $2018 \quad$ Published: January 18, 2018

Copyright: Motoshima et al. This is an open-access article distributed under the terms of the Creative Commons Attribution License 3.0 (CC BY 3.0), which permits unrestricted use, distribution, and reproduction in any medium, provided the original author and source are credited.

\section{ABSTRACT}

The prognostic implications of human epidermal growth receptor 2 (HER2) heterogeneity in gastric cancer (GC) are not well established. Therefore, the aim of the present study was to determine to the effect of HER2 status on the prognosis of GC patients. We retrieved data on 248 pathologically-confirmed, consecutive patients with primary adenocarcinoma of the stomach or gastro-esophageal junction who underwent surgical resection at Kurume University Medical Center between July 2000 and December 2012. HER2 status was classified as HER2 positive or negative and HER2 heterogeneity or homogeneity. The endpoint was overall survival (OS), which was compared using the generalized Wilcoxon test. HER2 status was positive in 36 patients $(\mathbf{1 4 . 5 \% )}$ ) and negative in 212 patients $(85.5 \%)$. Among the 36 HER2 positive patients, 25 patients (69.4\%) had HER2 heterogeneity and the remaining 11 patients $(30.6 \%)$ had HER2 homogeneity. Among the 141 patients with stage III or IV disease, the prognosis of the HER2 homogeneity group was significantly worse than that of the HER2 heterogeneity group ( $p=0.019$; median OS 193 and 831 days, respectively). The prognosis was not significantly different between the HER2 positive group and the HER2 negative group ( $p$ $=0.84$; median OS 552 and 556 days, respectively). The present study was conducted with small samples, however, the results of the study suggest that HER2 homogeneity but not HER2 positivity may represent a prognostic indicator in GC.

\section{INTRODUCTION}

The role of human epidermal growth receptor 2 (HER2) in breast cancer (BC) has been widely studied since the late 1980s [1-4] and has recently been established as a biomarker of poor prognosis in $\mathrm{BC}$ patients $[5,6]$, whereas in gastric cancer (GC), the role of HER2 as a biomarker of poor prognosis remains unclear [7]. Moreover, there is a growing concern that HER2 heterogeneity in $\mathrm{BC}$ may influence prognosis $[8,9]$. However, the effect of HER2 heterogeneity on prognosis of $\mathrm{GC}$ patients also remains unclear.
The HER2 targeted agent trastuzumab has been shown to be effective and safe in patients with HER2 positive metastatic $\mathrm{BC}[10-12]$ and is now established as a standard initial treatment in HER2 positive BC patients [13-15]. Furthermore, the emerging HER2 targeted agents lapatinib [16] and trastuzumab emtansine (T-DM1) [17] have also been shown to be effective and safe in this patient population. Owing to the effects of these anti-HER 2 targeted agents, HER 2 positive $\mathrm{BC}$ is no longer associated with a poor prognosis $[18,19]$. In GC, trastuzumab has also been shown to be effective and safe in the treatment of patients with HER2 positive metastatic 
or unresectable disease, regardless of conflicting HER2 prognostic values [20]. However, lapatinib and T-DM1 have failed to demonstrate efficacy in HER2 positive GC patients [21-23]. According to Matsuoka et al. [24], the efficacy of HER2 targeted agents has been shown to be more limited than expected in GC patients.

It is clear that the clinical implications of HER2 are markedly different between BC and GC patients. With respect to the biological nature of HER2, the frequency of HER2 heterogeneity differs between HER2 positive GC and $\mathrm{BC}$ patients, being $45 \%-79 \%$ [25-28] and $11 \%-40 \%$ $[8,9,29-33]$, respectively. This difference in frequency may explain the different clinical implications of HER2. In $\mathrm{GC}$, most studies on HER2 heterogeneity have focused on pathological issues [27, 28, 34-40], although two studies to our knowledge have focused on the prognostic implications [25, 26]. These two studies have reported conflicting results concerning the prognosis of HER2 heterogeneity compared with that of HER2 homogeneity. The effect of HER2 heterogeneity on prognosis of GC patients thus remains to be sufficiently elucidated.

The aim of the present study was to determine the differences in the prognosis of GC patients according to HER2 status and thus to clarify the potential of HER2 as a biomarker of prognosis in GC patients with HER2 heterogeneity.

\section{RESULTS}

\section{Clinicopathological characteristics and HER2 status}

Data corresponding to a total of 248 patients were retrieved. HER2 status was positive in 36 patients (14.5\%) and negative in 212 patients (85.5\%). Among the 36 HER2 positive patients, 25 patients (69.4\%) had HER2 heterogeneity and the remaining 11 patients $(30.6 \%)$ had HER2 homogeneity. The clinicopathological characteristics and HER2 status of the 248 patients are summarized in Table 1. Regarding the quality control of surgically resected samples, HER2 positivity rates did not show any significant difference between the two terms of the study period (July 2000 to December 2006, and January 2007 to December 2012) $(p=0.12)$.

\section{Prognosis}

The median observation period was 831.5 days (range: 9-5741 days). The overall number of events was 124 cases $(50 \%)$, and the number of events according to pathologic TNM stage was 6 cases $(9.2 \%)$ in stage I, 8 cases $(19.0 \%)$ in stage II, 35 cases $(58.3 \%)$ in stage III, and 75 cases $(92.6 \%)$ in stage IV. The number of events is summarized according to HER2 status and pathologic TNM stage in Table 2.

\section{Patients with stage III and IV disease}

Given the small number of events reported in patients with stage I and II disease and the administration of targeted HER2 therapy to patients with advanced and recurrence GC, we examined the prognosis of the 141 patients with stage III and IV disease. Trastuzumab-based chemotherapy was administered for two patients with recurrent HER2 positive GC, one of whom had HER2 homogeneity and one HER2 heterogeneity. The number of cycles of trastuzumab-based chemotherapy was 12 cycles for the HER2 homogeneity patient and 3 cycles for the HER2 heterogeneity patient. The clinicopathological characteristics of the 141 patients with stage III and IV disease, according to HER2 status, are summarized in Table 3. Tumors classified as intestinal type, based on Lauren classification, were significantly more frequent ( $p=0.021$ ) in HER2 positive compared with HER2 negative disease. Pathological subtypes, also based on Lauren classification, were not significantly different between the HER2 heterogeneity group and the HER2 homogeneity group.

\section{Overall survival}

We compared overall survival (OS) between the HER2 heterogeneity group and the HER2 homogeneity group. The prognosis of the HER2 homogeneity group was significantly worse than that of the HER2 heterogeneity group $(p=0.019$; $n=9$ and $n=16$, respectively; median OS 193 and 831 days, respectively) using the generalized Wilcoxon test (Figure 1). Subsequently, we compared OS between the HER2 positive group and the HER2 negative group and found no significant difference ( $p=0.84 ; n=25$ and $n=116$, respectively; median OS 552 and 556 days, respectively) using the generalized Wilcoxon test (Figure 2).

Excluding the two patients who received trastuzumab-based chemotherapy, the prognosis of the HER2 homogeneity group was significantly worse than that of the HER2 heterogeneity group $(p=0.015 ; n=8$ and $n=15$, respectively; median OS 156 and 1193 days, respectively) using the generalized Wilcoxon test (Supplementary Figure 1). We also compared OS between the HER2 positive group and the HER2 negative group and found no significant difference $(p=0.67 ; n=23$ and $n=116$, respectively; median OS 441 and 556 days, respectively) using the generalized Wilcoxon test (Supplementary Figure 2).

\section{DISCUSSION}

The present study revealed that the prognosis was significantly different between the HER2 heterogeneity group and the HER2 homogeneity group in patients with resectable primary adenocarcinoma of the stomach or gastro-esophageal junction. Overall, the HER2 homogeneity group had a significantly worse prognosis 
Table 1: Clinicopathological characteristics and HER2 status of the enrolled patients

\begin{tabular}{|c|c|c|c|c|c|c|c|}
\hline \multirow{2}{*}{ Variables } & \multicolumn{2}{|c|}{ HER2 positive } & \multirow{2}{*}{$\begin{array}{c}\text { Heterogeneity vs. } \\
\text { Homogeneity } \\
p \text {-value }\end{array}$} & \multicolumn{2}{|c|}{ HER2 status } & \multirow{2}{*}{$\begin{array}{l}\text { Positive vs. } \\
\text { Negative } \\
p \text {-value }\end{array}$} & \multirow{2}{*}{$\begin{array}{c}\text { Total } \\
(n=248)\end{array}$} \\
\hline & $\begin{array}{l}\text { Heterogeneity } \\
\quad(n=25)\end{array}$ & $\begin{array}{l}\text { Homogeneity } \\
\quad(n=11)\end{array}$ & & $\begin{array}{l}\text { Positive } \\
(n=36)\end{array}$ & $\begin{array}{l}\text { Negative } \\
(n=212)\end{array}$ & & \\
\hline Age (years) & & & $0.16^{\mathrm{b}}$ & & & $0.052^{\mathrm{b}}$ & \\
\hline Median & 70 & 65 & & 67.5 & 66 & & 66 \\
\hline Range & $47-86$ & $51-81$ & & $47-86$ & $38-88$ & & $38-88$ \\
\hline Advanced age, $\%(n)$ & & & $0.026^{\mathrm{c}}$ & & & $0.072^{\mathrm{c}}$ & \\
\hline$\geq 65$ years & $88.0(22)$ & $54.5(6)$ & & $77.8(28)$ & $62.3(132)$ & & $64.5(160)$ \\
\hline Sex, $\%(n)$ & & & $0.064^{\mathrm{c}}$ & & & $0.35^{\mathrm{c}}$ & \\
\hline Male & $60.0(15)$ & $90.9(10)$ & & $69.4(25)$ & $61.3(130)$ & & $62.5(155)$ \\
\hline Operative method, \% $(n)$ & & & $0.46^{\mathrm{d}}$ & & & $0.23^{\mathrm{d}}$ & \\
\hline Distal gastrectomy & $72.0(18)$ & $63.6(7)$ & & $69.4(25)$ & $61.8(131)$ & & $62.9(156)$ \\
\hline Total gastrectomy & $28.0(7)$ & $27.3(3)$ & & $27.8(10)$ & $32.5(69)$ & & $31.9(79)$ \\
\hline Proximal gastrectomy & 0 & $9.1(1)$ & & $2.8(1)$ & $4.2(9)$ & & $4.0(10)$ \\
\hline Pylorus-preserving gastrectomy & 0 & 0 & & 0 & $1.4(3)$ & & $1.2(3)$ \\
\hline Pathologic TNM stage, $\%(n)$ & & & $0.14^{\mathrm{d}}$ & & & $0.10^{\mathrm{c}}$ & \\
\hline I & $20.0(5)$ & 0 & & $13.9(5)$ & $28.3(60)$ & & $26.2(65)$ \\
\hline II & $16.0(4)$ & $18.2(2)$ & & $16.7(6)$ & $17.0(36)$ & & $16.9(42)$ \\
\hline III & $44.0(11)$ & $27.3(3)$ & & $38.9(14)$ & $21.7(46)$ & & $24.2(60)$ \\
\hline IV & $20.0(5)$ & $54.5(6)$ & & $30.5(11)$ & $33.0(70)$ & & $32.7(81)$ \\
\hline Lauren classification, $\%(n)$ & & & $0.83^{\mathrm{c}}$ & & & $0.0002^{\mathrm{c}}$ & \\
\hline Intestinal type & $76.0(19)$ & $72.7(8)$ & & $75.0(27)$ & $41.5(88)$ & & $46.4(115)$ \\
\hline Diffuse type & $24.0(6)$ & $27.3(3)$ & & $25.0(9)$ & $58.5(124)$ & & $53.6(133)$ \\
\hline Depth of tumor invasion, $\%(n)$ & & & $0.87^{\mathrm{d}}$ & & & $0.38^{\mathrm{d}}$ & \\
\hline Mucosa & $8.0(2)$ & 0 & & $5.6(2)$ & $15.1(32)$ & & $13.7(34)$ \\
\hline Submucosa & $8.0(2)$ & 0 & & $5.6(2)$ & $3.3(7)$ & & $3.6(9)$ \\
\hline Muscularis propria & $12.0(3)$ & $18.2(2)$ & & $13.9(5)$ & $11.3(24)$ & & $11.7(29)$ \\
\hline Subserosa & $16.0(4)$ & $27.3(3)$ & & $19.4(7)$ & $10.9(23)$ & & $12.1(30)$ \\
\hline Serosa and peritoneal cavity & $52.0(13)$ & $54.5(6)$ & & $52.7(19)$ & $55.2(117)$ & & $54.9(136)$ \\
\hline Adjacent structures & $4.0(1)$ & 0 & & $2.8(1)$ & $4.2(9)$ & & $4.0(10)$ \\
\hline Lymphatic invasion, $\%(n)$ & & & $0.53^{\mathrm{d}}$ & & & $0.21^{\mathrm{c}}$ & \\
\hline ly0 & $12.0(3)$ & $9.1(1)$ & & $11.1(4)$ & $22.6(48)$ & & $21.0(52)$ \\
\hline ly1 & $28.0(7)$ & $9.1(1)$ & & $22.2(8)$ & $27.8(59)$ & & $27.0(67)$ \\
\hline ly2 & $32.0(8)$ & $54.5(6)$ & & $38.9(14)$ & $25.5(54)$ & & $27.4(68)$ \\
\hline ly3 & $28.0(7)$ & $27.3(3)$ & & $27.8(10)$ & $24.1(51)$ & & $24.6(61)$ \\
\hline Venous invasion, \% $(n)$ & & & $0.57^{\mathrm{d}}$ & & & $0.029^{c}$ & \\
\hline v0 & $16.0(4)$ & 0 & & $11.1(4)$ & $25.5(54)$ & & $23.4(58)$ \\
\hline v1 & $28.0(7)$ & $27.3(3)$ & & $27.8(10)$ & $28.8(61)$ & & $28.6(71)$ \\
\hline v2 & $20.0(5)$ & $36.4(4)$ & & $25.0(9)$ & $29.5(62)$ & & $28.6(71)$ \\
\hline v3 & $36.0(9)$ & $36.4(4)$ & & $36.1(13)$ & $16.5(35)$ & & $19.4(48)$ \\
\hline \multicolumn{8}{|l|}{ IHC score, $\%(n)$} \\
\hline 0 or $1+$ & 0 & 0 & & 0 & $99.1(210)$ & & $84.7(210)$ \\
\hline $2+$ & $36.0(9)$ & 0 & & $25.0(9)$ & $0.9(2)$ & & $4.4(11)$ \\
\hline $3+$ & $64.0(16)$ & $100(11)$ & & $75.0(27)$ & 0 & & $10.9(27)$ \\
\hline \multicolumn{8}{|l|}{$\begin{array}{l}\text { DISH, \% }(n) \\
\text { (among the IHC } \\
\text { score of } 2+\text { cases) }\end{array}$} \\
\hline Negative & 0 & 0 & & 0 & $100(2)$ & & $2(18.2)$ \\
\hline Positive & $100(9)$ & 0 & & $100(9)$ & 0 & & $9(81.8)$ \\
\hline
\end{tabular}


Table 2: Number of events among the 248 enrolled patients according to HER2 status and pathologic TNM stage

\begin{tabular}{lcccc}
\hline $\begin{array}{l}\text { Pathologic TNM stage, } \\
\text { \% (number of events/n) }\end{array}$ & $\begin{array}{c}\text { HER2 status } \\
(\boldsymbol{n}=\mathbf{2 5})\end{array}$ & $\begin{array}{c}\text { Homogeneity } \\
(\boldsymbol{n}=\mathbf{1 1})\end{array}$ & $\begin{array}{c}\text { Negative } \\
(\boldsymbol{n}=\mathbf{2 1 2})\end{array}$ & $\begin{array}{c}\text { Total } \\
(\boldsymbol{n}=\mathbf{2 4 8})\end{array}$ \\
\hline I & $40.0(2 / 5)$ & $0(0 / 0)$ & $6.7(4 / 60)$ & $9.2(6 / 65)$ \\
II & $25.0(1 / 4)$ & $0(0 / 2)$ & $19.4(7 / 36)$ & $19.0(8 / 42)$ \\
III & $36.4(4 / 11)$ & $66.7(2 / 3)$ & $63.0(29 / 46)$ & $58.3(35 / 60)$ \\
IV & $100(5 / 5)$ & $100(6 / 6)$ & $91.4(64 / 70)$ & $92.6(75 / 81)$ \\
Total & $48.0(12 / 25)$ & $72.7(8 / 11)$ & $49.1(104 / 212)$ & $50.0(124 / 248)$ \\
\hline
\end{tabular}

Abbreviation: HER2, human epidermal growth factor receptor 2.

Table 3: Clinicopathological characteristics of the 141 enrolled patients with stage III and IV disease, according to HER2 status

\begin{tabular}{|c|c|c|c|c|c|c|}
\hline \multirow[b]{2}{*}{ Variables } & \multicolumn{2}{|c|}{ HER2 positive } & \multirow{2}{*}{$\begin{array}{c}\text { Heterogeneity vs. } \\
\text { Homogeneity } \\
p \text {-value }\end{array}$} & \multicolumn{2}{|c|}{ HER2 status } & \multirow{2}{*}{$\begin{array}{c}\text { Positive vs } \\
\text { Negative } \\
p \text {-value }\end{array}$} \\
\hline & $\begin{array}{l}\text { Heterogeneity } \\
\quad(n=16)\end{array}$ & $\begin{array}{c}\text { Homogeneity } \\
(n=9)\end{array}$ & & $\begin{array}{l}\text { Positive } \\
(n=25)\end{array}$ & $\begin{array}{l}\text { Negative } \\
(n=116)\end{array}$ & \\
\hline Age (years) & & & $0.39^{\mathrm{b}}$ & & & $0.25^{\mathrm{b}}$ \\
\hline Median & 70.5 & 66.7 & & 69.0 & 66.5 & \\
\hline Range & $47-84$ & $51-81$ & & $47-84$ & $38-87$ & \\
\hline Advanced age, $\%(n)$ & & & $0.18^{\mathrm{c}}$ & & & $0.34^{\mathrm{c}}$ \\
\hline$\geq 65$ years & $81.3(13)$ & $55.6(5)$ & & $72.0(18)$ & $62.1(72)$ & \\
\hline Sex, $\%(n)$ & & & $0.14^{\mathrm{c}}$ & & & $0.43^{\mathrm{c}}$ \\
\hline Male & $62.5(10)$ & $88.9(8)$ & & $72.0(18)$ & $63.8(74)$ & \\
\hline Operative method, $\%(n)$ & & & $0.47^{\mathrm{d}}$ & & & $0.26^{\mathrm{d}}$ \\
\hline Distal gastrectomy & $68.8(11)$ & $55.6(5)$ & & $64.0(16)$ & $55.2(64)$ & \\
\hline Total gastrectomy & $31.2(5)$ & $33.3(3)$ & & $32.0(8)$ & $42.2(49)$ & \\
\hline Proximal gastrectomy & 0 & $11.1(1)$ & & $4.0(1)$ & $2.6(3)$ & \\
\hline Pathologic TNM stage, $\%(n)$ & & & $0.085^{\mathrm{d}}$ & & & $0.14^{\mathrm{c}}$ \\
\hline III & $68.8(11)$ & $33.3(3)$ & & $56.0(14)$ & $39.7(46)$ & \\
\hline IV & $31.2(5)$ & $66.7(6)$ & & $44.0(11)$ & $60.3(70)$ & \\
\hline Lauren classification, $\%(n)$ & & & $0.83^{\mathrm{c}}$ & & & $0.021^{\mathrm{c}}$ \\
\hline Intestinal type & $62.5(10)$ & $66.7(6)$ & & $64.0(16)$ & $38.8(45)$ & \\
\hline Diffuse type & $37.5(6)$ & $33.3(3)$ & & $36.0(9)$ & $61.2(71)$ & \\
\hline Depth of tumor invasion, $\%(n)$ & & & $0.48^{\mathrm{d}}$ & & & $0.11^{\mathrm{d}}$ \\
\hline Muscularis propria & 0 & $11.1(1)$ & & $4.0(1)$ & $3.4(4)$ & \\
\hline Subserosa & $18.7(3)$ & $33.3(3)$ & & $24.0(6)$ & $7.8(9)$ & \\
\hline Serosa and peritoneal cavity & $75.0(12)$ & $55.6(5)$ & & $68.0(17)$ & $81.0(94)$ & \\
\hline Adjacent structures & $6.3(1)$ & 0 & & $4.0(1)$ & $7.8(9)$ & \\
\hline Lymphatic invasion, $\%(n)$ & & & $0.29^{\mathrm{d}}$ & & & $0.53^{\mathrm{d}}$ \\
\hline ly0 & 0 & $11.1(1)$ & & $4.0(1)$ & $2.6(3)$ & \\
\hline
\end{tabular}




\begin{tabular}{lcccc} 
ly1 & $18.7(3)$ & 0 & $12.0(3)$ & $23.3(27)$ \\
ly2 & $37.5(6)$ & $55.6(5)$ & $44.0(11)$ & $35.3(41)$ \\
ly3 & $43.8(7)$ & $33.3(3)$ & $40.0(10)$ & $38.8(45)$ \\
Venous invasion, \% (n) & 0 & $0.86^{\mathrm{d}}$ & $0.087^{\mathrm{d}}$ \\
v0 & $25.0(4)$ & $22.2(2)$ & $24.0(6)$ & $31.0(36)$ \\
v1 & $18.7(3)$ & $33.3(3)$ & $24.0(6)$ & $37.9(44)$ \\
v2 & $56.3(9)$ & $44.5(4)$ & $52.0(13)$ & $25.9(30)$ \\
v3 & & 0 & $0.9(6)$ \\
\hline
\end{tabular}

a Results were considered statistically significant when $p$-values were less than 0.05 .

${ }^{\mathrm{b}} t$-test.

${ }^{\mathrm{c}}$ chi-square test.

'Fisher's exact test.

Abbreviation: HER2, human epidermal growth factor receptor 2.

compared with the HER2 heterogeneity group. However, the prognosis was not significantly different between the HER2 positive group and the HER2 negative group.

Our findings show that HER2 homogeneity is associated with a significantly worse prognosis because of the presence of relatively large amounts of HER2 positive components compared with HER2 heterogeneity. Subsequently, the lack of a significant difference in prognosis between the HER2 positive group and the HER2 negative group may be explained by the observation that
HER2 positive GC is primarily associated with HER2 heterogeneity. In the present study, the HER2 heterogeneity group accounted for $69.4 \%$ of the HER2 positive group, which is within the range of previous reports $(45 \%-79 \%)$ [25-28]. The conflicting HER2 prognostic values between $\mathrm{GC}$ and $\mathrm{BC}$ can be reasonably explained by the markedly different frequency of HER2 heterogeneity between HER2 positive GC and BC. It is unclear whether the role of HER2 as a biomarker of poor prognosis in $\mathrm{GC}$ might be to the result of this difference in frequency, whereby the prognostic value

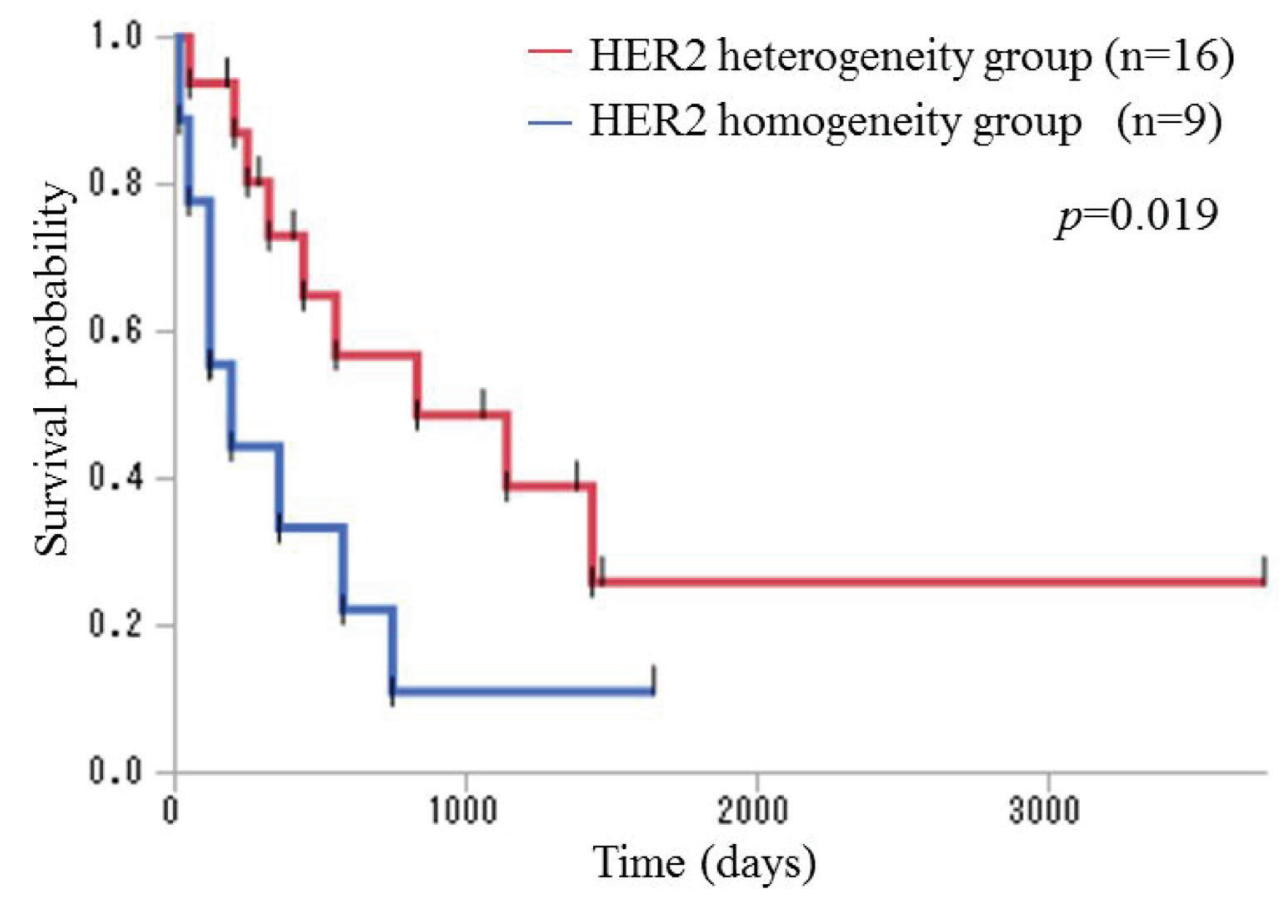

Figure 1: Kaplan-Meier overall survival curves for patients with stage III and IV disease in the HER2 heterogeneity and HER2 homogeneity groups. The prognosis of the HER2 homogeneity group was significantly worse than that of the HER2 heterogeneity group ( $p=0.019 ; n=9$ and $n=16$, respectively; median OS 193 and 831 days, respectively) using the generalized Wilcoxon test. 


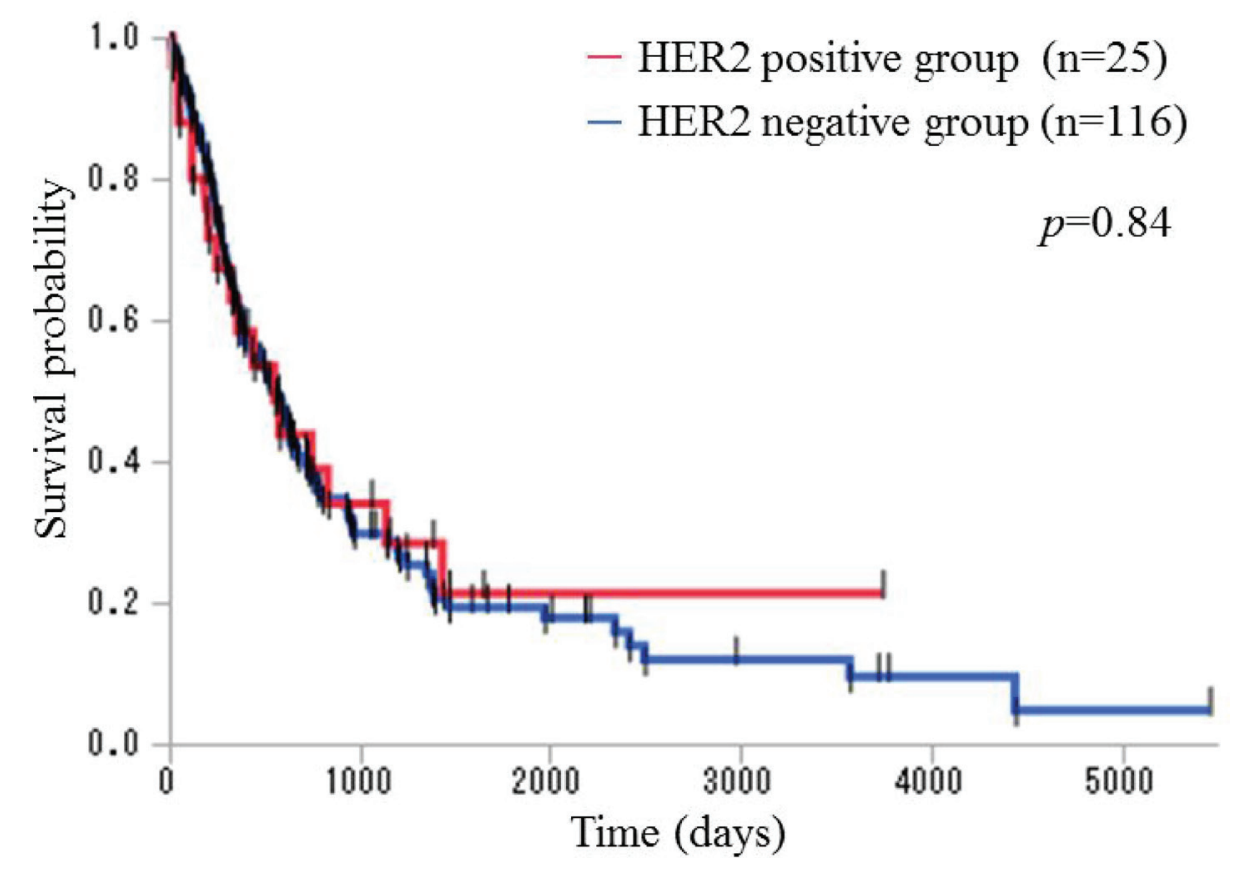

Figure 2: Kaplan-Meier overall survival curves for patients with stage III and IV disease in the HER2 positive and the HER2 negative groups. The prognosis was not significantly different between the HER2 positive group and the HER2 negative group ( $p=0.84 ; n=25$ and $n=116$, respectively; median OS 552 and 556 days, respectively) using the generalized Wilcoxon test.

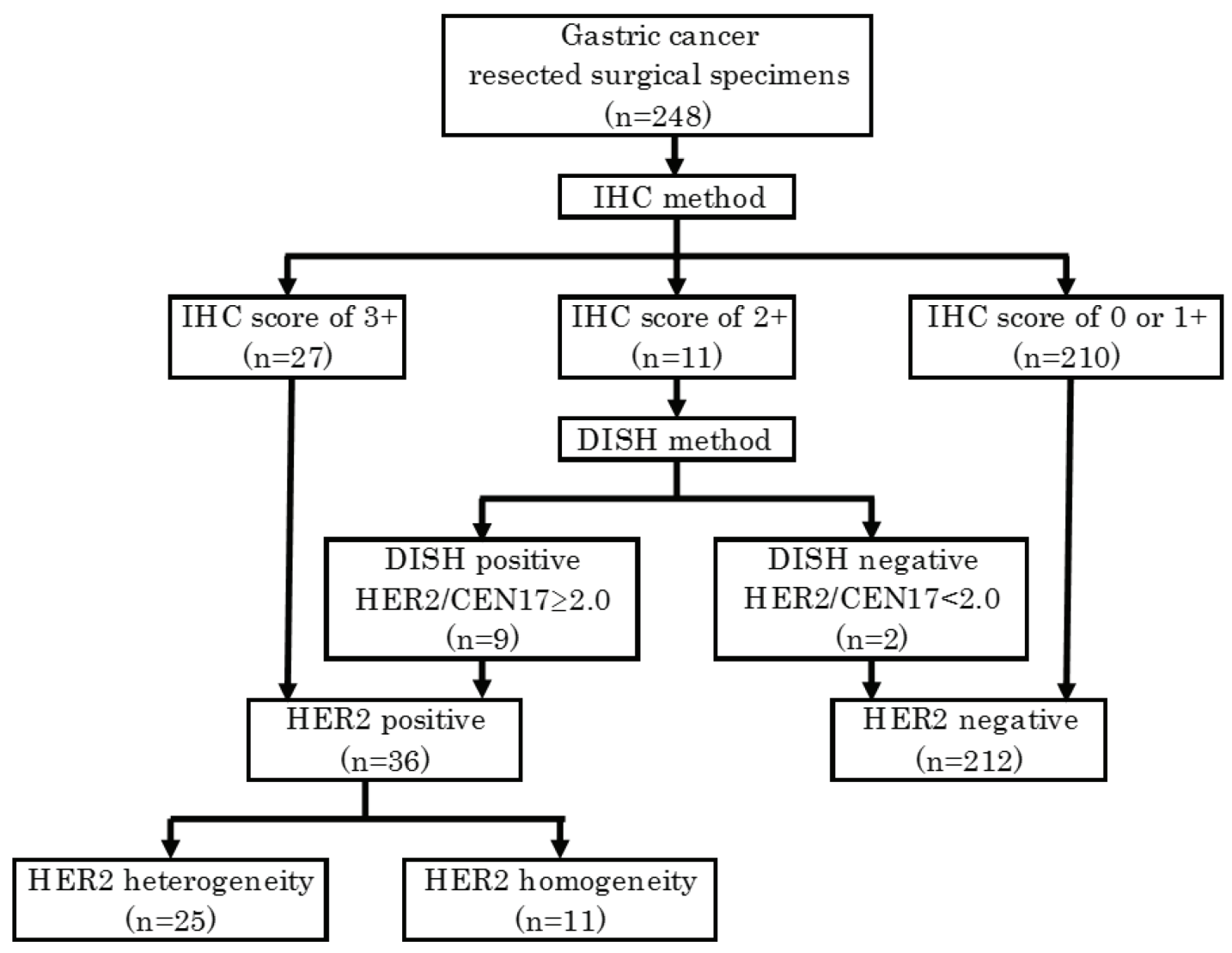

Figure 3: Classification of HER2 status. 
might be determined by the extent of HER 2 heterogeneity in HER2 positive GC. In addition, the pathological subtype may impact prognosis. In diffuse type GC tumors, most of which are poorly differentiated, patients are more likely to have a poorer prognosis compared with intestinal type GC tumors, most of which are well to moderately differentiated. Intestinal type tumors are more frequent in HER2 positive GC compared with diffuse type tumors [41]. In the present study, tumors classified as intestinal type tumors were significantly more frequent in the HER2 positive group compared with the HER2 negative group and accounted for $64.0 \%$ of the HER2 positive group and $38.8 \%$ of the HER 2 negative group. In addition, the frequency of intestinal type tumors was not significantly different between the HER2 heterogeneity group and the HER2 homogeneity group. According to Qiu et al. [41], HER2 positivity was not an independent prognostic factor in GC and the evaluation of HER2 positivity combined with Lauren classification provided a better prognostic value. However, in BC, HER2 positivity is frequent in high nuclear grade $\mathrm{BC}$ has been shown to be clinically aggressive [42]. Different features of pathological subtypes between HER2 positive $\mathrm{GC}$ and $\mathrm{BC}$ may also contribute to the conflicting HER2 prognostic values.

Two studies to date have focused on of the effect of HER2 heterogeneity on GC prognosis. Lee et al. [26] examined a single institutional cohort of Korean GC patients and found that the HER2 homogeneity group had a significantly worse prognosis, evaluated by diseasefree survival, compared with the HER2 heterogeneity group. Although a different evaluation of survival probability was used, the results of the present study support these findings. Kurokawa et al. [25] examined a multi-institutional cohort of Japanese GC patients and found no significant difference in OS between the HER2 heterogeneity group and the HER2 homogeneity group. In addition, they demonstrated that the HER2 positive group had a significantly worse prognosis than the HER2 negative group. Although the reason for the inconsistency between the Kurokawa et al. study and our results is unclear, the frequency of events was $78.0 \%(110 / 141)$ among patients with stage III-IV GC disease in the present study. Therefore, we considered the prognosis of most cases in the present study to have been accurately evaluated, and the subsequent results are justifiable.

Improved understanding of the molecular biology of $\mathrm{GC}$ and the development of targeted molecular therapy is likely to improve the prognosis of GC patients [43, 44]. Trastuzumab, a monoclonal antibody targeting HER2, is used in the treatment of patients with HER2 positive, inoperable, locally advanced, recurrent, or metastatic GC, although individualized treatment for GC according to HER2 status has not been done. However, HER2 positive GC patients frequently develop resistance to trastuzumab [45, 46] through a mechanism that remains poorly understood, although intratumoral heterogeneity may represent one cause of cancer treatment resistance [47, 48]. According to Lee et al. [8], intratumoral HER2 heterogeneity had a poorer treatment response to trastuzumab and was associated with a worse prognosis in patients with HER2 positive metastatic BC. In patients with HER2 positive GC, the evaluation of treatment response to trastuzumab, according to HER2 status, is therefore warranted.

Regarding the processing of pathological specimens, the importance of sustainable quality control is emphasized in the recommendations for HER2 testing in BC by the American Society of Clinical Oncology/College of American Pathologists guidelines [49]. HER2 positivity rates were unaffected by the length of the storage period, indicative of the proper management of pathological samples in our institution.

Our study had some limitations, including the small sample, retrospective design. Second, the data were derived from a single institution, meaning that the interpretation of the results must be generalized with caution. Third, trastuzumab-based chemotherapy was administered to two patients with recurrent HER2 positive GC among the 141 patients with stage III and IV disease. The exclusion of these two patients extended the median OS of the HER2 homogeneity and HER2 positive groups, and the differences in OS increased between the HER2 homogeneity group and the HER2 heterogeneity group as well as between the HER2 positive group and the HER2 negative group. We assume that trastuzumab is more effective in HER2 homogeneity patients and less effective in HER2 heterogeneity patients, indicating that it may not be possible to observe differences in the effect of trastuzumab in HER2 homogeneity BC patients receiving postoperative trastuzumab administration, although this should be evaluated in future studies.

In summary, the present study indicates that prognostic values may differ according to HER2 status, with HER2 homogeneity patients having a worse prognosis compared with HER2 heterogeneity patient. Extrapolations from the present study may be explained by the difference between BC and GC in the clinical implications of HER2 as a biomarker of a poor prognosis. With respect to HER2 heterogeneity and homogeneity in GC, a more precise prognostic prediction may be available for HER2 positive patients. Moreover, responsiveness to anti-HER2 targeted agents in GC may have a potential to vary between HER2 heterogeneity patients and HER2 homogeneity patients. Therefore, well-structured, prospective studies are required to evaluate the prognosis or responsiveness to anti-HER2 targeted agents of HER2 heterogeneity in GC patients, distinct from HER2 homogeneity.

\section{MATERIALS AND METHODS}

\section{Subjects}

This retrospective cohort study included Japanese patients with primary adenocarcinoma of the stomach 
or gastro-esophageal junction who underwent surgical resection at the Kurume University Medical Center, Japan, between July 2000 and December 2012. The 258 consecutive patients were pathologically confirmed to have adenocarcinoma of the stomach or gastro-esophageal junction. Of the 258 patients, two patients diagnosed with remnant GC and eight patients who had received preoperative chemotherapy were excluded from the study. Postoperative adjuvant chemotherapy is indicated for pathologic TNM stage II and stage III GC. For GC patients with pathologic TNM stage IV or with recurrent disease and whose general condition and major organ functions are preserved, chemotherapy is also indicated. In addition, after March 2011, trastuzumab-based chemotherapy was considered in patients with recurrent HER2 positive GC. None of the 248 enrolled patients had received trastuzumab therapy or radiotherapy prior to surgery. This study was approved by the ethics committee of Kurume University (no. 13128) and conducted in accordance with the principles of the Declaration of Helsinki.

\section{Clinical variables}

The following clinical data were obtained from the patients' medical records: age at the time of surgery, advanced age (defined as $\geq 65$ years), sex, and operative method (distal gastrectomy, total gastrectomy, proximal gastrectomy, or pylorus-preserving gastrectomy).

\section{Pathological variables}

All cases with resected surgical specimens were retrieved and each slide was reviewed by two independent pathologists (M.M. and R.Y.). Pathological variables were evaluated by consensus of the two pathologists. All surgically resected tissue specimens were fixed in $10 \%$ buffered formalin, and formalin fixation time was 6 hours-72 hours. Tissue specimens were embedded in paraffin and processed routinely, and $4-\mu \mathrm{m}$ sections were stained with hematoxylin and eosin (H\&E). Pathologic TNM stage, pathological classification, depth of tumor invasion, lymphatic and venous invasion, and HER2 status were evaluated. The International Union against Cancer/ TNM system was applied to classify pathologic TNM stage $[50,51]$. Pathological classification was based on Lauren classification (intestinal type or diffuse type) [52]. Depth of tumor invasion (mucosa, submucosa, muscularis propria, subserosa, serosa and peritoneal cavity, or adjacent structures), lymphatic invasion (ly0, ly1, ly2, or ly3), and venous invasion (v0, v1, v2, or v3) were classified in accordance with the Japanese classification of gastric carcinoma [53].

\section{HER2 status}

HER2 status determined in the pathological samples by immunohistochemistry (IHC) and dual color in situ hybridization (DISH). An anti-HER2/neu rabbit monoclonal primary antibody (clone 4B5, Ventana, Tucson, AZ, USA) was used for IHC. HER2 and chromosome 17 probes were detected using two-color chromogenic in situ hybridization in formalin-fixed, paraffin-embedded tissue specimens in accordance with the manufacturer's protocol. IHC staining and a HER2 DISH DNA probe cocktail assay were performed using a fully automated Ventana Benchmark XT staining system (Ventana, Tucson, AZ, USA). Antigen retrieval was carried out by heating the sections in EDTA $(\mathrm{pH} 8.5)$ in accordance with the manufacturer's protocol. IHC staining was classified as a score of $3+, 2+, 1+$, or 0 to evaluate the degree of HER2 protein overexpression using the HER2 scoring system [51]. HER2 DISH was classified as positive or negative with respect to HER2 gene status by calculating the ratio of the HER2/chromosome 17 centromere (CEN17); a HER2/CEN17 ratio of $\geq 2$ was defined as HER2 DISH positive and a HER2/CEN17 ratio of $<2$ was defined as HER2 DISH negative.

HER2 status, which was classified as HER2 positive or negative, was assessed with using the IHC score and the HER2/CEN17 ratio. HER2 positive or negative status was then classified in accordance with the Japanese Society of Pathology HER2 pathological diagnosis guidelines GC. Samples with an IHC score of $3+$ were defined as HER2 positive, 0 or $1+$ were defined as HER2 negative, and $2+$ were defined as "HER2 equivocally". For the latter samples, additional HER2 gene status was evaluated, with HER2 DISH positive samples defined as HER2 positive and HER2 DISH negative samples defined as HER2 negative (Figure 3 ).

HER2 positive samples were classified into two categories: HER2 heterogeneity or homogeneity. HER2 heterogeneity was defined as $10 \%-90 \%$ of tumor cells showing HER2 protein overexpression in samples with an IHC score of $3+$ and or an IHC score of $2+$ with DISH positive status. HER2 homogeneity was defined as $>90 \%$ of tumor cells showing HER2 protein overexpression in samples with an IHC score of $3+$. To evaluate quality control of the surgically resected samples in our institution, we divided the cases into two terms by date of the surgical resection with the former term from July 2000 to December 2006 and the latter term from January 2007 to December 2012. We then compared HER2 positivity rates between samples from the two terms using the chi-square test.

\section{Statistical analysis}

The study endpoint was OS, which was defined as in the number of days between the date of GC surgery and the date of death from any cause or last follow-up. The vital status of patients was verified through patients' medical records in May 2016. OS was estimated using the Kaplan-Meier method, and the differences in OS between the subgroups were compared using the generalized Wilcoxon test. Patients' characteristics were compared 
using the chi-square test or Fisher's exact test for discrete variables, and the $t$-test for continuous variables. Results were considered statistically significant when $p$-values were $<0.05$. Statistical analyses were conducted using $\mathrm{JMP}^{\circledR} 13$ software (SAS Institute Inc., Cary, NC, USA).

\section{ACKNOWLEDGMENTS}

The authors thank Prof. Kyogo Itoh from the Cancer Vaccine Center, Kurume University Medical Center for his review of and valuable comments on our study.

\section{CONFLICTS OF INTEREST}

The authors declare that they have no conflicts of interest.

\section{REFERENCES}

1. Slamon DJ, Clark GM, Wong SG, Levin WJ, Ullrich A, McGuire WL. Human breast cancer: correlation of relapse and survival with amplification of the HER-2/neu oncogene. Science. 1987; 4785:177-82.

2. Slamon DJ, Godolphin W, Jones LA, Holt JA, Wong SG, Keith DE, Levin WJ, Stuart SG, Udove J, Ullrich A. Studies of the HER-2/neu proto-oncogene in human breast and ovarian cancer. Science. 1989; 244:707-12.

3. Tandon AK, Clark GM, Chamness GC, Ullrich A, McGuire WL. HER-2/neu oncogene protein and prognosis in breast cancer. J Clin Oncol. 1989; 7:1120-8.

4. Zeillinger R, Kury F, Czerwenka K, Kubista E, Sliutz G, Knogler W, Huber J, Zielinski C, Reiner G, Jakesz R. HER-2 amplification, steroid receptors and epidermal growth factor receptor in primary breast cancer. Oncogene. 1989; 4:109-14.

5. Xia W, Chen JS, Zhou X, Sun PR, Lee DF, Liao Y, Zhou BP, Hung MC. Phosphorylation/cytoplasmic localization of $\mathrm{p} 21 \mathrm{Cip} 1 / \mathrm{WAF} 1$ is associated with HER2/neu overexpression and provides a novel combination predictor for poor prognosis in breast cancer patients. Clin Cancer Res. 2004; 10:3815-24.

6. Choi YH, Ahn JH, Kim SB, Jung KH, Gong GY, Kim MJ, Son BH, Ahn SH, Kim WK. Tissue microarray-based study of patients with lymph node-negative breast cancer shows that HER2/neu overexpression is an important predictive marker of poor prognosis. Ann Oncol. 2009; 20:1337-43.

7. Duraes C, Almeida GM, Seruca R, Oliveira C, Carneiro F. Biomarkers for gastric cancer: prognostic, predictive or targets of therapy? Virchows Arch. 2014; 464:367-78.

8. Lee HJ, Seo AN, Kim EJ, Jang MH, Suh KJ, Ryu HS, Kim YJ, Kim JH, Im SA, Gong G, Jung KH, Park IA, Park SY. HER2 heterogeneity affects trastuzumab responses and survival in patients with HER2-positive metastatic breast cancer. Am J Clin Pathol. 2014; 142:755-66.
9. Seol H, Lee HJ, Choi Y, Lee HE, Kim YJ, Kim JH, Kang E, Kim SW, Park SY. Intratumoral heterogeneity of HER2 gene amplification in breast cancer: its clinicopathological significance. Mod Pathol. 2012; 25:938-48.

10. Cobleigh MA, Vogel CL, Tripathy D, Robert NJ, Scholl S, Fehrenbacher L, Wolter JM, Paton V, Shak S, Lieberman G, Slamon DJ. Multinational study of the efficacy and safety of humanized anti-HER 2 monoclonal antibody in women who have HER2-overexpressing metastatic breast cancer that has progressed after chemotherapy for metastatic disease. J Clin Oncol. 1999; 17:2639-48.

11. Slamon DJ, Leyland-Jones B, Shak S, Fuchs H, Paton V, Bajamonde A, Fleming T, Eiermann W, Wolter J, Pegram M, Baselga J, Norton L. Use of chemotherapy plus a monoclonal antibody against HER2 for metastatic breast cancer that overexpresses HER2. N Engl J Med. 2001; 344:783-92.

12. Vogel CL, Cobleigh MA, Tripathy D, Gutheil JC, Harris LN, Fehrenbacher L, Slamon DJ, Murphy M, Novotny WF, Burchmore M, Shak S, Stewart SJ, Press M. Efficacy and safety of trastuzumab as a single agent in firstline treatment of HER2-overexpressing metastatic breast cancer. J Clin Oncol. 2002; 20:719-26.

13. Piccart-Gebhart MJ, Procter M, Leyland-Jones B, Goldhirsch A, Untch M, Smith I, Gianni L, Baselga J, Bell R, Jackisch C, Cameron D, Dowsett M, Barrios CH, et al. Trastuzumab after adjuvant chemotherapy in HER2-positive breast cancer. N Engl J Med. 2005; 353:1659-72.

14. Smith I, Procter M, Gelber RD, Guillaume S, Feyereislova A, Dowsett M, Goldhirsch A, Untch M, Mariani G, Baselga J, Kaufmann M, Cameron D, Bell R, et al. 2-year follow-up of trastuzumab after adjuvant chemotherapy in HER2-positive breast cancer: a randomised controlled trial. Lancet. 2007; 369:29-36.

15. Gianni L, Dafni U, Gelber RD, Azambuja E, Muehlbauer S, Goldhirsch A, Untch M, Smith I, Baselga J, Jackisch C, Cameron D, Mano M, Pedrini JL, et al. Treatment with trastuzumab for 1 year after adjuvant chemotherapy in patients with HER2-positive early breast cancer: a 4-year follow-up of a randomised controlled trial. Lancet Oncol. 2011; 12:236-44.

16. Geyer CE, Forster J, Lindquist D, Chan S, Romieu CG, Pienkowski T, Jagiello-Gruszfeld A, Crown J, Chan A, Kaufman B, Skarlos D, Campone M, Davidson N, et al. Lapatinib plus capecitabine for HER2-positive advanced breast cancer. N Engl J Med. 2006; 355:2733-43.

17. Welslau M, Dieras V, Sohn JH, Hurvitz SA, Lalla D, Fang L, Althaus B, Guardino E, Miles D. Patient-reported outcomes from EMILIA, a randomized phase 3 study of trastuzumab emtansine (T-DM1) versus capecitabine and lapatinib in human epidermal growth factor receptor 2-positive locally advanced or metastatic breast cancer. Cancer. 2014; 120:642-51.

18. Dawood S, Broglio K, Buzdar AU, Hortobagyi GN, Giordano SH. Prognosis of women with metastatic breast 
cancer by HER2 status and trastuzumab treatment: an institutional-based review. J Clin Oncol. 2010; 28:92-8.

19. Figueroa-Magalhaes MC, Jelovac D, Connolly RM, Wolff AC. Treatment of HER2-positive breast cancer. Breast. 2014; 23:128-36.

20. Bang YJ, Van Cutsem E, Feyereislova A, Chung HC, Shen L, Sawaki A, Lordick F, Ohtsu A, Omuro Y, Satoh T, Aprile G, Kulikov E, Hill J, et al. Trastuzumab in combination with chemotherapy versus chemotherapy alone for treatment of HER2-positive advanced gastric or gastrooesophageal junction cancer (ToGA): a phase 3, open-label, randomised controlled trial. Lancet. 2010; 376:687-97.

21. Hecht JR, Bang YJ, Qin SK, Chung HC, Xu JM, Park JO, Jeziorski K, Shparyk Y, Hoff PM, Sobrero A, Salman P, Li J, Protsenko SA, et al. Lapatinib in Combination With Capecitabine Plus Oxaliplatin in Human Epidermal Growth Factor Receptor 2-Positive Advanced or Metastatic Gastric, Esophageal, or Gastroesophageal Adenocarcinoma: TRIO013/LOGiC - A Randomized Phase III Trial. J Clin Oncol. 2016; 34:443-51.

22. Satoh T, Xu RH, Chung HC, Sun GP, Doi T, Xu JM, Tsuji A, Omuro Y, Li J, Wang JW, Miwa H, Qin SK, Chung IJ, et al. Lapatinib plus paclitaxel versus paclitaxel alone in the second-line treatment of HER2-amplified advanced gastric cancer in Asian populations: TyTAN - a randomized, phase III study. J Clin Oncol. 2014; 32:2039-49.

23. Kang YK, Shah MA, Ohtsu A, Van Cutsem E, Ajani JA, Van Der Hors T, Harle-Yge ML, Piao Y, Althaus B, ThussPatience PC. A randomized, open-label, muticenter, adaptive phase $2 / 3$ study of trastuzumab emtansine (T-DM1) versus a taxane (TAX) in patients with previously treated HER2-positive locally advanced or metastatic gastric/gastroesophageal junction adenocarcinoma (LA/ MGC/GEJC). J Clin Oncol. 2016; 34 (suppl 4S): abstr 5.

24. Matsuoka T, Yashiro M. Recent advances in the HER2 targeted therapy of gastric cancer. World J Clin Cases. 2015; $3: 42-51$

25. Kurokawa Y, Matsuura N, Kimura Y, Adachi S, Fujita J, Imamura H, Kobayashi K, Yokoyama Y, Shaker MN, Takiguchi S, Mori M, Doki Y. Multicenter large-scale study of prognostic impact of HER2 expression in patients with resectable gastric cancer. Gastric Cancer. 2015; 18:691-7.

26. Lee HE, Park KU, Yoo SB, Nam SK, Park do J, Kim HH, Lee HS. Clinical significance of intratumoral HER2 heterogeneity in gastric cancer. Eur J Cancer. 2013; 49:1448-57.

27. Lee S, de Boer WB, Fermoyle S, Platten M, Kumarasinghe MP. Human epidermal growth factor receptor 2 testing in gastric carcinoma: issues related to heterogeneity in biopsies and resections. Histopathology. 2011; 59:832-40.

28. Yang J, Luo H, Li Y, Li J, Cai Z, Su X, Dai D, Du W, Chen T, Chen M. Intratumoral heterogeneity determines discordant results of diagnostic tests for human epidermal growth factor receptor (HER) 2 in gastric cancer specimens. Cell Biochem Biophys. 2012; 62:221-8.

29. Murthy SS, Sandhya DG, Ahmed F, Goud KI, Dayal M, Suseela K, Rajappa SJ. Assessment of HER2/Neu status by fluorescence in situ hybridization in immunohistochemistryequivocal cases of invasive ductal carcinoma and aberrant signal patterns: a study at a tertiary cancer center. Indian J Pathol Microbiol. 2011; 54:532-8.

30. Ohlschlegel C, Zahel K, Kradolfer D, Hell M, Jochum W. HER2 genetic heterogeneity in breast carcinoma. J Clin Pathol. 2011; 64:1112-6.

31. Chang MC, Malowany JI, Mazurkiewicz J, Wood M. 'Genetic heterogeneity' in HER2/neu testing by fluorescence in situ hybridization: a study of 2,522 cases. Mod Pathol. 2012; 25:683-8.

32. Allison KH, Dintzis SM, Schmidt RA. Frequency of HER2 heterogeneity by fluorescence in situ hybridization according to CAP expert panel recommendations: time for a new look at how to report heterogeneity. Am J Clin Pathol. 2011; 136:864-71.

33. Bartlett AI, Starcyznski J, Robson T, Maclellan A, Campbell FM, van de Velde CJ, Hasenburg A, Markopoulos C, Seynaeve C, Rea D, Bartlett JM. Heterogeneous HER2 gene amplification: impact on patient outcome and a clinically relevant definition. Am J Clin Pathol. 2011; 136:266-74.

34. Saito T, Kondo C, Shitara K, Ito Y, Saito N, Ikehara Y, Yatabe Y, Yamamichi K, Tanaka H, Nakanishi H. Comparison of intratumoral heterogeneity of HER2 expression between primary tumor and multiple organ metastases in gastric cancer: Clinicopathological study of three autopsy cases and one resected case. Pathol Int. 2015; 65:309-17.

35. Kanayama K, Imai H, Yoneda M, Hirokawa YS, Shiraishi T. Significant intratumoral heterogeneity of human epidermal growth factor receptor 2 status in gastric cancer: A comparative study of immunohistochemistry, FISH, and dual-color in situ hybridization. Cancer Sci. 2016; 107:536-42.

36. Stahl P, Seeschaaf C, Lebok P, Kutup A, Bockhorn M, Izbicki JR, Bokemeyer C, Simon R, Sauter G, Marx AH. Heterogeneity of amplification of HER2, EGFR, CCND1 and MYC in gastric cancer. BMC Gastroenterol. 2015; 15:7.

37. Nishida Y, Kuwata T, Nitta H, Dennis E, Aizawa M, Kinoshita T, Ohtsu A, Ochiai A. A novel gene-protein assay for evaluating HER2 status in gastric cancer: simultaneous analyses of HER2 protein overexpression and gene amplification reveal intratumoral heterogeneity. Gastric Cancer. 2015; 18:458-66.

38. Potts SJ, Huff SE, Lange H, Zakharov V, Eberhard DA, Krueger JS, Hicks DG, Young GD, Johnson T, WhitneyMiller CL. Tissue pattern recognition error rates and tumor heterogeneity in gastric cancer. Appl Immunohistochem Mol Morphol. 2013; 21:21-30. 
39. Kim MA, Lee HJ, Yang HK, Bang YJ, Kim WH. Heterogeneous amplification of ERBB2 in primary lesions is responsible for the discordant ERBB2 status of primary and metastatic lesions in gastric carcinoma. Histopathology. 2011; 59:822-31.

40. Onsum MD, Geretti E, Paragas V, Kudla AJ, Moulis SP, Luus L, Wickham TJ, McDonagh CF, Macbeath G, Hendriks BS. Single-cell quantitative HER2 measurement identifies heterogeneity and distinct subgroups within traditionally defined HER2-positive patients. Am J Pathol. 2013; 183:1446-60.

41. Qiu M, Zhou Y, Zhang X, Wang Z, Wang F, Shao J, Lu J, Jin Y, Wei X, Zhang D, Wang F, Li Y, Yang D, Xu R. Lauren classification combined with HER2 status is a better prognostic factor in Chinese gastric cancer patients. BMC Cancer. 2014; 14:823.

42. Tsuda HH. Prognostic and predictive value of c-erbB-2 (HER-2/neu) gene amplification in human breast cancer. Breast Cancer. 2001; 8:38-44.

43. Dittmar Y, Settmacher U. Individualized treatment of gastric cancer: Impact of molecular biology and pathohistological features. World J Gastrointest Oncol. 2015; 7:292-302.

44. Wadhwa R, Song S, Lee JS, Yao Y, Wei Q, Ajani JA. Gastric cancer-molecular and clinical dimensions. Nat Rev Clin Oncol. 2013; 10:643-55.

45. Lee J, Bass AJ, Ajani JA. Gastric Adenocarcinoma: An Update on Genomics, Immune System Modulations, and Targeted Therapy. Am Soc Clin Oncol Educ Book. 2016; 35:104-11.

46. Arienti C, Zanoni M, Pignatta S, Del Rio A, Carloni S, Tebaldi M, Tedaldi G, Tesei A. Preclinical evidence of multiple mechanisms underlying trastuzumab resistance in gastric cancer. Oncotarget. 2016; 7:18424-39. http://doi. org/10.18632/oncotarget.7575.
47. Gerlinger M, Rowan AJ, Horswell S, Larkin J, Endesfelder D, Gronroos E, Martinez P, Matthews N, Stewart A, Tarpey P, Varela I, Phillimore B, Begum S, et al. Intratumor heterogeneity and branched evolution revealed by multiregion sequencing. N Engl J Med. 2012; 366:883-92.

48. Venkatesan S, Swanton C. Tumor Evolutionary Principles: How Intratumor Heterogeneity Influences Cancer Treatment and Outcome. Am Soc Clin Oncol Educ Book. 2016; 35:e141-9.

49. Wolff AC, Hammond ME, Hicks DG, Dowsett M, McShane LM, Allison KH, Allred DC, Bartlett JM, Bilous M, Fitzgibbons P, Hanna W, Jenkins RB, Mangu PB, et al. Recommendations for human epidermal growth factor receptor 2 testing in breast cancer: American Society of Clinical Oncology/College of American Pathologists clinical practice guideline update. Arch Pathol Lab Med. 2014; 138:241-56.

50. Stomach. In: Sobin L, Gospodarowicz M, Wittekind C, editors. TNM Classification of Malignant Tumours. 7th ed. Weinheim, Germany: Wiley-Blackwell; 2009; 69-73.

51. Hofmann M, Stoss O, Shi D, Buttner R, van de Vijver M, Kim W, Ochiai A, Rüschoff J, Henkel T. Assessment of a HER2 scoring system for gastric cancer: results from a validation study. Histopathology. 2008; 52:797-805.

52. Fenoglio-Preiser C, Muñoz N, Carneiro F, Powell S, Correa P, Rugge M. Tumours of the stomach. In: Hamilton S, Aaltonen, L., editor. WHO classification of tumours Pathology and genetics of the digestive system. Lyon: IARC press; 2000; 37-67.

53. Japanese Gastric Cancer Association. Japanese classification of gastric carcinoma: 3rd English education. Gastric Cancer. 2011; 14:101-12. 